\title{
Research on Modeling Intrahousehold Interactions from the Perspective of Space-Time Constraints
}

\author{
Liangpeng Gao, ${ }^{1}$ Yanjie Ji, ${ }^{1}$ Yang Liu, ${ }^{1}$ and Baohong $\mathrm{He}^{2}$ \\ ${ }^{1}$ School of Transportation, Southeast University, 35 Jinxianghe Rd, Nanjing, Jiangsu, China \\ ${ }^{2}$ Faculty of Transportation Engineering, Kunming University of Science \& Technology, 727 South Jingming Rd, Kunming, \\ Yunnan, China \\ Correspondence should be addressed to Yanjie Ji; jiyanjie@seu.edu.cn
}

Received 10 November 2016; Accepted 15 January 2017; Published 9 February 2017

Academic Editor: Cengiz Çinar

Copyright (C) 2017 Liangpeng Gao et al. This is an open access article distributed under the Creative Commons Attribution License, which permits unrestricted use, distribution, and reproduction in any medium, provided the original work is properly cited.

\begin{abstract}
Interactions among family members can yield valuable information for interpreting individual travel decisions. Typically, each family member plays a set role and travel decisions are made by considering the combined needs of household members. This study investigates both multiactivity and multiperson interactions in urban nuclear families and proposes the novel concepts of "activity-restriction degree" and "activity-constraint niche" to quantify the degree of space-time constraints within time geography. A structural equation model is employed to analyze intrahousehold interactions based on individual activity-travel patterns during the workday. The results indicate that the links between family members reflect behavioral responses (with constraints) between individuals and other family members. Household interaction constraints not only influence individual travel decisions but also affect the realization of the household activity for everyone. These interactions lead to reasonable adjustments and mutual support and to the identification of efficient activity patterns that meet the demands of the entire household.
\end{abstract}

\section{Introduction}

Joint decision-making has consistently been found to have an effect on activity-travel behavior that is stronger than the individual context associated with personal scheduling, behavioral disposition, and sociodemographic features [1]. Moreover, the household is frequently regarded as a fundamental unit in activity-based travel demand analysis. For instance, in a family, each member plays a set role, makes decisions based on the needs of other members, and tends to share various household resources $[2,3]$. This introduces a conclusive perspective that the household's main impact on individual decision-making may be concentrated in two ways. First, a family is a complex group, and all decisions made must account for systemic interrelation among members [4]. Human activity-travel patterns are rarely a simple output of individual choice behavior and are instead often influenced by both household resources and the environment $[5,6]$. Second, as a result of the space-time continuity of travel and activities, participation by different family members in individual or household activities leads to disruptive or harmonious effects on the planning procedures of daily schedules. These are traces of evidence supporting the notion that the activity-travel demands of children in the household have a significant impact on the behavioral decision-making of their parents [7]. Therefore, household activity-travel interactions must be examined from both multiactivity and multiperson perspectives.

In recent decades, a stream of research has attempted to analyze and determine the activity-travel mechanism of individuals and families. In the 1970s, researchers began to focus on individual behavioral choices and household tasks resulting from comprehensive household decision-making, and these researches led to a conceptual framework from which the actual and potential behavioral interactions of households could be explored [8-10]. Through the mid1990s, as the research focus was refined, advancements in academic research enabled students to attain a clear grasp of the spatiotemporal character of household decision-making processes, expanding into more concrete research areas such as time and task allocation, individual or joint activity participation, and travel mode choices [11, 12]. Moreover, 
the corresponding methods and models of these studies have gradually improved [13]. As detailed in Timmermans [14], the application models of the household interaction mechanism were divided into three types: microsimulation models, utility-maximizing models, and rule-based models.

(i) The Microsimulation Model. This model focuses on the mechanisms at work behind decision-making and travel and may refer to the standards of rule-based or utilitymaximizing models. For instance, Přibyl and Goulias [15] applied their microsimulation model to individual decisionmaking processes and interactions among household members. The algorithm they developed aimed to replicate the activity patterns of household interactions and was aggregated into two main phases: the estimation phase and the simulation phase. Another microsimulation model is the agent-based system, which combines household interactions and allocates tasks among household members [16]. Arentze et al. [17] assumed that agents had identical perceptions of household needs and that household activities were integrated into individual schedules if the decision thresholds met the necessary requirements and maximized utility within the family. These thresholds commonly include expenditures, location, transportation facilities, and other space-time factors.

(ii) The Utility-Maximizing Model. This model includes two submodels: the discrete choice model and the time allocation model [18]. The discrete choice model aims to achieve the maximum utility of household activity-travel patterns and primarily evaluates the effects of external factors (social attributes, transportation facilities, and polices) on household decision-making behavior. The decision rule in this model is based on the assumption that a household attempts to maximize its utility [19-23]. The time allocation model also focuses on external characteristics (land use, route directness, tour elements, and residential and commercial densities), as they influence diverse household activity-travel interactions $[24,25]$. The research emphasis associated with this model is the time-use of individual and joint activities [26, 27].

(iii) The Rule-Based Model. The methodologies of this model differ from the utility-maximizing model in that household activity-travel decisions follow set principles rather than attempting to achieve maximum utility. Research in this area focuses on activity generation, the location selection of discretionary activities, the rescheduling of household activities, and other relevant factors [28-31]. Approaches to these principles include minimum household disutility rules $[32,33]$ and adherence to constraint-based rules [34, 35]. There are other articles, such as Chow and Nurumbetova [36] research, focusing on modeling travel activity agendas with a linear programming method which synthesized the hypothesis conditions of these two rules.

The previous literature contains examples of integral research on joint intrahousehold activity decisions. Due to their disaggregated hypotheses of the real world, such models are particularly well suited to describing the complexity of interaction mechanisms. However, although some scholars have introduced concepts like "need," "potential," and "stress" to be incorporated into descriptions of household decision processes [29, 37], these measurement methods may be less flexible in their explanations of how household members adjust their preferred schedules to cope with different types of constraints which arise as a result of the rigidity of joint activities or travels [38], which is particularly true for Chinese families. Building on all these reasons, this study aims to answer the following questions:

(1) In a Chinese family, how is a household schedule best set and are there any discoverable rules in the decision-making process?

(2) How do Chinese households manage individual activities and travel when these arrangements are diverted by other household activities?

The remainder of the paper is organized as follows. Section 2 describes the theory of household activity-travel decision-making and presents the main concepts and their definitions. Sections 3 and 4 detail the theoretical model developed in this study and explain the model estimation results based on travel diary data collected in Kunming, China. Section 5 concludes the paper and maps out future research issues.

\section{Theory}

2.1. Mechanism of Household Activity-Travel Decisions. As discussed above in Section 1, household activity-travel decision-making is a typical group decision behavior that is not a simple composition of all the members but is instead a complex process related to many activity-travel elements within the household environment. The primary goal is to construct an efficient behavior pattern for the household in which each person can overcome his/her travel barriers and meet activity-related needs under a certain degree of timespace constraints. In other words, the entire household coordinates the interactive constraints of each member according to multi-item activities/travel. Figure 1 shows a flowchart of the household activity-travel decision-making process.

2.2. Activity Space-Time Consumption and the Degree of Activity Restriction. According to time geography theory, individual behavior involves consumption of space-time: the space-time consumption of a person who participates in one activity determines all possibilities of participating in other activities and is thus called a "constraint." Activity-travel behavior is depicted in the two-dimensional space-time travel chain shown in Figure 2. The horizontal line represents an inactive process, and the diagonal line represents a mobile process. Each family member's line represents the speed corresponding to the means of transport that he/she used. In this study, "speed" is a uniform value associated with transport, which ignores the impact of the outside traffic environment in considering the travel mode and use as the criteria to determine each "mean" speed.

The trip chain in Figure 2 demonstrates that, on the survey day, the focal family member completed two work 


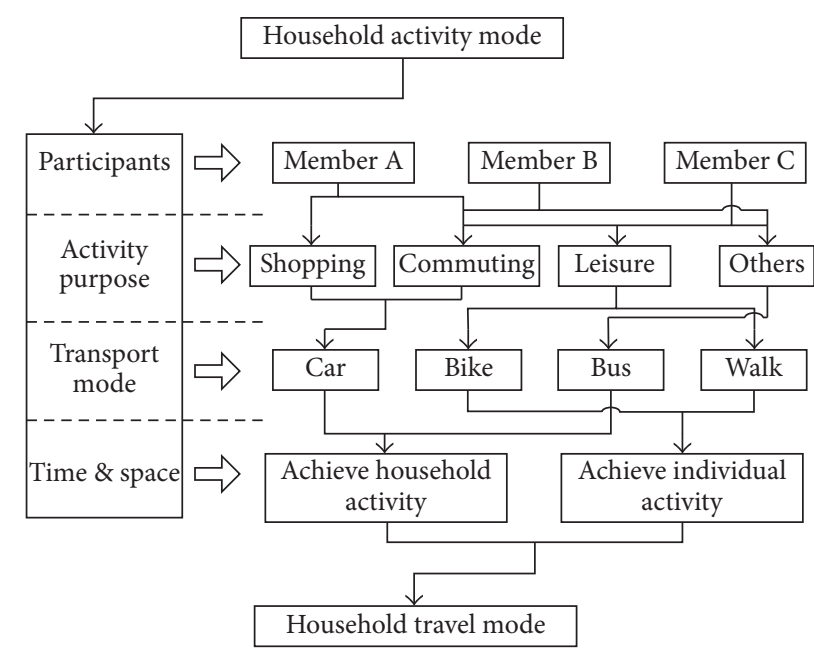

FIGURE 1: Household activity-travel decision-making flowchart.

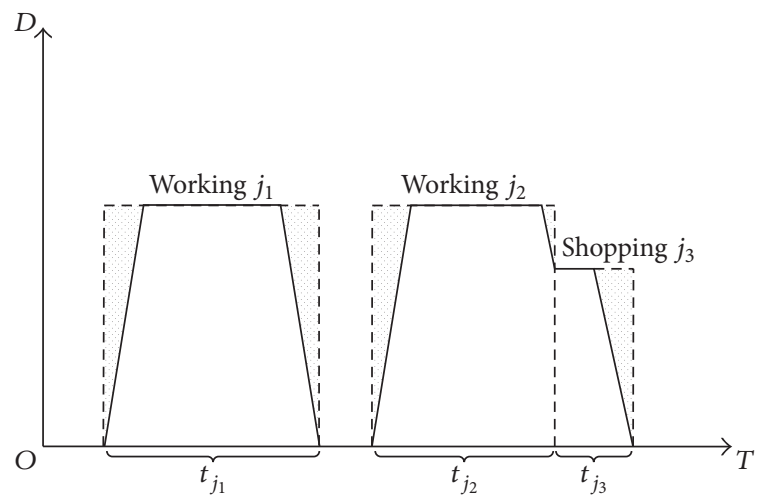

FIgURE 2: Two-dimensional space-time trip chain of a commuter.

activities and one shopping activity in a total of five trips. All these actions required that he/she expend the corresponding space-time resources, and the individual was not always able to finish two different activities within the same time window. Thus, the space-time limitations of various activities determine the probability that the family member will engage in other activities or travel. For example, in Figure 2, the commuter should complete his/her commute and remain at the workplace during time periods $t_{j 1}$ and $t_{j 2}$, and he/she can shop only during the remainder of his/her work time, such as during lunch hours or after work. Therefore, in this paper, we provide the concept of "activity space-time consumption," which is represented by $A_{i j}$ to estimate the consumption of space-time resources caused by person $i$ traveling to activity $j$. The detailed measurement method is expressed using the following formula:

$$
A_{i j}=\sum_{j=1}^{m} \int_{D\left(f_{i}(t)\right)} f_{i}(t) d t
$$

$f_{j}(t)$ is the travel distance function of individual $i$ as he or she performs daily trip-chaining activities (Euclidean distances are here used for locations), and $D\left(f_{j}(t)\right)$ is the definition domain of $f_{j}(t) . D\left(f_{j}(t)\right)$ ranges from 0 to 24 , corresponding to the available hours in one day, and $m$ is the maximum value of the activity count. Based on (1), we propose the measure method of "activity constraint" $T_{i}$, which combines the space-time expended resources $A_{i}$ and the associated opportunity cost (the resources are not actually expended and are unusable) represented by $O_{i}$ in (2). In the above example, the "activity constraint" of this commuter is the proportion of rectangles $\mathrm{A}, \mathrm{B}$, and $\mathrm{C}$. See the following formula:

$$
T_{i}=A_{i}+O_{i}=\sum_{j=1}^{m} d_{i j} \cdot t_{i j}
$$

where $d_{i j}$ is the travel distance over which individual $i$ moves from home to the activity location $j$ and $t_{i j}$ is the activity duration time plus the travel time of individual $i$ performing activity $j$. The total constraint upon individual $i$ in one day is expressed as follows:

$$
Y_{i}=\frac{T_{i}-\min \left(T_{i}\right)}{\max \left(T_{i}\right)-\min \left(T_{i}\right)},
$$

where $Y_{i}$ is defined as the "activity-restriction degree," which is the normalized transfer function of the "activity constraint." This variable can be used over the entire sample to describe the possibility that traveler $i$ participated in other activities during the survey day. Obviously, the definition of "activity-restriction degree" can help researchers calculate the strength of the total restriction, and its increasing value signifies a lower likelihood of engaging in behaviors.

\subsection{Household Activity-Constraint Niche and Its Dimension.} Time geography is an applied theory, and the space-time prism proposed is frequently used to visualize and measure the societal spatiotemporal activity patterns throughout the day [39]. Other scholars have subsequently supplemented several approaches and concepts to ensure that the theory was more suitable for the research requirements [40, 41]. However, there are only a few studies that have used the space-time prism or its extended application as the analytical tool to explore household activity-travel interaction [7, 42]. Obviously, household activity-travel patterns involve group decision-making behavior, where the individual family members, particularly in a Chinese nuclear family, communicate or cooperate with one another based on general household needs.

Figure 3 describes the workday space-time prisms of a Chinese nuclear family, in which activity-travel space forms the plane coordinates and time is the longitudinal axis. The image on the left is a common scenario in which the male parent completed his commuting activity during the workday and in which the female parent not only commuted but also was responsible for picking up the children. If the female parent cannot pick the children up, the male parent can adjust the commuting constraint accordingly to pick them up (Figure 3(b)). This study proposes a concept called the "household activity-constraint niche" to represent the relative restriction degree of individuals within household 


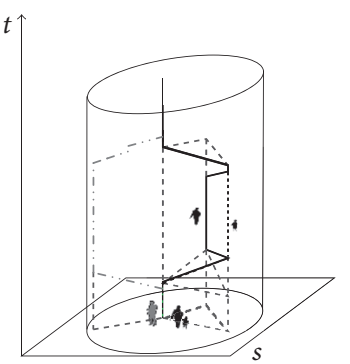

(a)
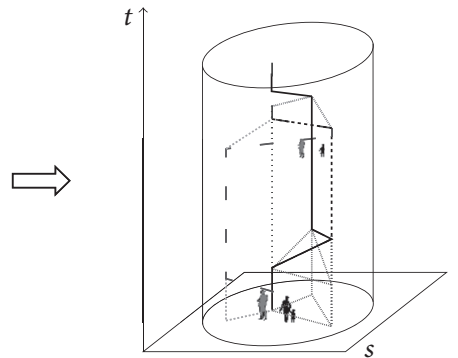

(b)
FIgURE 3: Space-time paths for a nuclear family.

member interactions; the household activity-constraint niche is defined as the proportion or segment into which the individual constraint level divides the total amount of household constraint. The detailed measurement method of this concept will be illustrated in the following subsection.

To highlight the relative restriction of individuals who participate in household activities and to emphasize the interconnectedness between members, this study resets the measuring index of activity types based on individual restrictions (as opposed to traditional activities that are used to build classification systems, such as subsistence, maintenance, and recreation activities). Previous studies [43] have identified the following five factors as influencing the activity-travel behavior of individuals: (1) situational constraints, which require a person, transport mode, and other scheduling resources to share the same space at the same time; (2) institutional constraints, such as opening hours, which influence the earliest and latest possible times to implement a particular activity; (3) household constraints, such as children who must be taken to school; (4) time constraints; and (5) spatial constraints. Of these five constraints, the situational constraints factor is the foundational assumption in our paper in which each household member and the corresponding transport mode would not be in the same spaces at different times under the intrahousehold arrangement and resource allocation plan. Moreover, institutional constraints will not be considered as a factor because the assumption is that individuals' participation in each activity occurs during the facilities' hours of operation. On this basis, this study selects the following three dimensions of constraint to classify the dataset.

(i) Time Constraints. Time constraints, including start-end times and duration times, limit the activity-travel behavior of those individuals who participate in time-fixed activities, such as commuting to work or school. As a result of time constraints, individuals must miss other activities and focus on finishing the current task.

(ii) Spatial Constraints. Spatial constraints limit the activitytravel behavior of individuals participating in location-fixed activities, such as going to the hospital, attending social events, and engaging in business activities with fixed locations but relatively flexible times. Notably, some types of activities in daily life require individuals to complete a task not only at a fixed time but also at a fixed location.

(iii) Participant Constraints. Participant constraints refer to the influence and effects of household activities, such as taking the children to school, visiting family, participating in picnics, and providing transportation. These types of constraints typically demand that individuals finish their household tasks with the assistance of two or more family members, such that all participants in the activity should at least make time for the activity. It is fair to say that participant constraint is the dimension that most accurately reflects the initiative and positivity of intrahousehold collaboration.

\subsection{The Measurement Indicator of the Household Activity-} Constraint Niche. As discussed above, the activity-constraint niche is a relational variable that shows the restrictions of all the family members in the comparison. This study uses the concept of "activity-constraint niche breadth" as the measurement index, and this value is calculated in the following manner:

$$
P_{i, x}=\frac{Y_{i, x}}{Y_{H, x}}=\frac{Y_{i, x}}{\sum_{i=1}^{n} Y_{i, x}},
$$

where $P_{i, x}$ represents the activity-constraint niche of individual $i$ in the $x$ th constraint, $Y_{i, x}$ is the activity-restriction degree of person $i$ restricted by the $x$ th dimension, and $Y_{H, x}$ is the total number of household constraints, which includes person $i$ in the $x$ th dimension. For example, suppose in time constraint $x$ that the activity-restriction degree $Y_{i, x}$ of person $i$ is 0.35 and that the total activity-restriction degree $Y_{H, x}$ of his/her family is 0.7 , such that the activity-constraint niche breadth $P_{i, x}$ is 0.5 . Obviously, this formulation reflects the activity-constraint limitation of each member of the family, and the range of value is from 0 to 1 ; thus, when $P_{i, x}$ is equal to 0 , the person suffers no constraints in the household with regard to activity-travel decisions, and when $P_{i, x}$ is close to 1 , the person has a larger constraint in his/her household.

These indices represent interactions among individual activity-travel constraints in the same dimension. Multiperson activity-travel constraints can be better understood through a matrix that includes and describes all household members. The construction of this matrix is detailed as follows.

The household is represented as $\mathrm{m}$ and the dimension is $N$. Vector group $\left(\begin{array}{lllll}W_{1} & W_{2} & \cdots & W_{m}\end{array}\right)^{T}$ is the constraint condition of all household members, and vector $W_{i}=$ $\left(\begin{array}{llll}P_{i, x 1} & P_{i, x 2} & \cdots & P_{i, x N}\end{array}\right)$ is the activity-constraint niche breadth of person $i$. The shape of the household constraint matrix is as follows:

$$
\begin{aligned}
C & =\left(\begin{array}{llll}
W_{1} & W_{2} & \cdots & W_{M}
\end{array}\right)^{T} \\
& =\left[\begin{array}{cccc}
P_{1, x 1} & P_{1, x 2} & \cdots & P_{1, x N} \\
P_{2, x 1} & P_{2, x 2} & \cdots & P_{2, x N} \\
\vdots & \vdots & \ddots & \vdots \\
P_{m, x 1} & P_{m, x 2} & \cdots & P_{m, x N}
\end{array}\right] .
\end{aligned}
$$


TABLE 1: Classification results of parents based on constrained clustering.

\begin{tabular}{|c|c|c|c|c|c|c|c|}
\hline \multirow[t]{2}{*}{ Name } & \multirow[t]{2}{*}{ Instruction } & \multicolumn{4}{|c|}{$\begin{array}{l}\text { Example of household } \\
\text { constraint matrix }\end{array}$} & Number & \multirow[t]{2}{*}{ Proportion } \\
\hline & & & 0.20 & 0.15 & 0.50 & & \\
\hline \multirow[t]{3}{*}{$C_{1}$} & $\begin{array}{l}\text { The participant constraints of parents are almost equal in these } \\
\text { families (niche breadth ranged from } 0.4 \text { to } 0.6 \text { ). }\end{array}$ & $C_{1}=$ & 0.30 & 0.25 & 0.50 & 47 & $13.51 \%$ \\
\hline & & & 0.50 & 0.60 & 0.00 & & \\
\hline & & & 0.60 & 0.45 & 0.25 & & \\
\hline \multirow[t]{3}{*}{$C_{2}$} & $\begin{array}{l}\text { The participant constraints of female parents are greater than those of } \\
\text { males (niche breadth is greater than or equal to } 0.6 \text { ). }\end{array}$ & $C_{2}=$ & 0.10 & 0.25 & 0.75 & 58 & $16.67 \%$ \\
\hline & & & 0.30 & 0.30 & $0.00=$ & & \\
\hline & & & 0.15 & 0.30 & 0.70 & & \\
\hline \multirow[t]{3}{*}{$C_{3}$} & $\begin{array}{l}\text { The participant constraints of male parent are greater than those of } \\
\text { females (niche breadth is greater than or equal to } 0.6 \text { ). }\end{array}$ & $C_{3}=$ & 0.45 & 0.35 & 0.30 & 34 & $9.77 \%$ \\
\hline & & & 0.40 & 0.35 & 0.00 & & \\
\hline & & & 0.30 & 0.55 & 0.00 & & \\
\hline \multirow[t]{2}{*}{$C_{4}$} & $\begin{array}{l}\text { The parents in these families do not have any household } \\
\text { activity/travel in the database. }\end{array}$ & $C_{4}=$ & 0.45 & 0.25 & 0.00 & 209 & $60.05 \%$ \\
\hline & & & 0.25 & 0.20 & 0.00 & & \\
\hline
\end{tabular}

Note. The row vectors of the matrix represent the father, mother, and child. The column vectors represent separate dimensions of the time, space, and the participant.

The matrix features two basic characteristics:

(1) Each matrix element ranges from 0 to 1 :

$$
P_{i, x N} \in[0,1] .
$$

(2) The sum of all the activity-constraint niche breadths in the same dimension equals 1 :

$$
P_{1, x N}+P_{2, x N}+\cdots+P_{m, x N}=1 \text {. }
$$

\section{Data Description and Modeling Framework}

3.1. Data Source and Descriptive Statistics. The data source of this research is a traditional travel survey consisting of family attributes and individual attributes from activity diaries obtained in Kunming, China, in the fall of 2011. The survey respondents were asked to record their activities and travel information for 24 hours. In the family attributes section, they recorded their home address, family size, type and number of employments (full-time/part-time), number of children, transportation options, and average household annual income. Individual information included gender, age, education, occupation, work address, and the length of daily commutes to work and/or school. The purposes of activity or travel (eleven in total) were divided into four main categories: personal commute (work, school, and business), personal leisure (shopping, recreation, and socializing), personal activities (doctor visits, returning home, and returning to work), and family affairs (shuttling children and joint activities, such as visiting friends or going home together). The activity-travel information also included travel times, purpose of travel (activity type), departure times, arrival times, starting places and destinations, and travel modes. The sample included typical Chinese nuclear families, which consist of parents and an unmarried child. Most urban nuclear families have only one child under the one-child policy in China (which is a unique consideration in the global context), and the parents are required to devote more time to caring for and accompanying their child themselves due to the child's dependence. Thus, intrahousehold interactions are particularly evident in this family type, which helps with the analysis of members' interaction mechanisms regarding urban household activity-travel.

Following the definition from the previous section, the niche breadth of "participant constraints" can reveal how household tasks were assigned based on the results of the calculation. At this point, we can verify whether there is a data skew problem and whether the dataset is suitable for building models for further research. Therefore, the 348 surveyed nuclear families were clustered into four groups as shown in Table 1: activity-sharing families $\left(C_{1}\right)$, female-bearing families $\left(C_{2}\right)$, male-bearing families $\left(C_{3}\right)$, and individualaffairs families $\left(C_{4}\right)$.

The survey data clearly show that individual-affairs families make up the highest percentage of families (approximately 60\%). This suggests that individual activities are the primary component of household activity-travel patterns of Kunming citizens on a typical weekday. However, the amount of household activity-travel also grew to a sizeable proportion of daily life, particularly when considering that brief or shortdistance household activity-travel was likely ignored during the questionnaire survey, which implies that there is no significant skewness in this dataset.

3.2. Modeling Framework. The main notion behind the constraint-based rule is that each activity-travel in the household pattern is made in an attempt to satisfy the needs of the entire family under relevant restrictions. Moreover, household activity-travel interactions involve the conflicting needs 


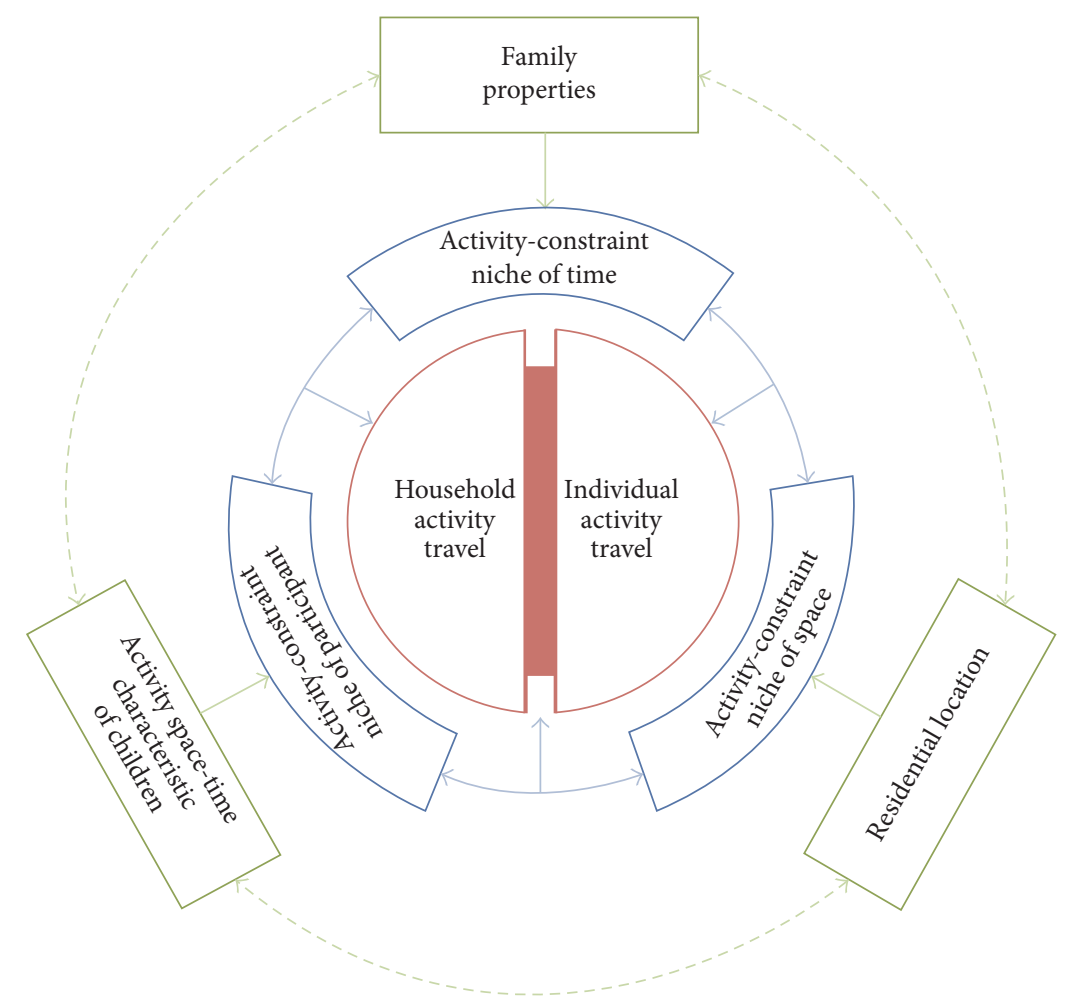

FIGURE 4: The conceptual model of household-based behavioral decision-making.

of individual family members. As intrahousehold activitytravel conflicts emerge, interaction mechanisms are created which function to adjust the individual decision-making behavior of each member. To understand this mechanism, an activity-travel mode is built to illustrate how family members mitigate activity-travel conflict. This is a repeat-adjusted cycle in which the constraints provide an environment for activity-travel decision-making. Within a household system, the relevant constraint environments can be divided into extrahousehold and intrahousehold constraints.

Extrahousehold constraints place household members within an objective environment and have an indirect effect on decision-making through specific social attributes that form the outer layer of the modeling framework, including the number of family cars, family size, children-based space-time constraints, and family income level. The intrahousehold constraint is the middle layer in the modeling framework and has a direct effect on household pattern building, including niche variables regarding time, space, and participant. The repeat-adjusted cycle of household patterns is the inner layer of the modeling framework. Figure 4 shows the conceptual model of household behavioral decisionmaking.

Observation variables were filtered before being utilized to construct models. Theoretically, the factors that influence household activity-travel behavior include the household environment, individual attributes, accessibility between jobs (or schools) and residential locations, and any activity restrictions. In an effort to build the simplest and most rational models, the explanatory and dependent variables were analyzed through linear correlation using SPSS Statistics 20.0. After rejecting any variables with correlation coefficients between -0.25 and +0.25 , the remaining endogenous variables were divided into four groups: household activity constraints, trip-chaining characteristics, duration of household/individual activities, and time consumption of household/individual travel. This study focuses on the manner in which household interactions work through the endogenous variables listed in Notations.

\section{Analysis Result}

4.1. Decision-Making Models and Household Interaction Model. Structural equation model (SEM), applied using AMOS 20.0, was employed to analyze the relevant data. Because the observed variables include interval data, rank data, and nominal data, the sample model would have failed to meet joint normal distribution. To account for this, model parameters were estimated using the least squares method. After adjusting the relationships between the model variables, the results were obtained as shown in Figures 5-7, neglecting all paths in which the correlation coefficients measured less than 0.25 or in which $p$ value was over 0.10 .

Among these, the interaction model (Figure 7) extracts the duration of the activity and the time consumed by travel as endogenous variables to detail the activity-travel behavior mechanism based on the decision-making models of parents (Figures 5-6). At the same time, the endogenous variables of the interaction model were compartmentalized into personal activity-travel and household activity-travel 


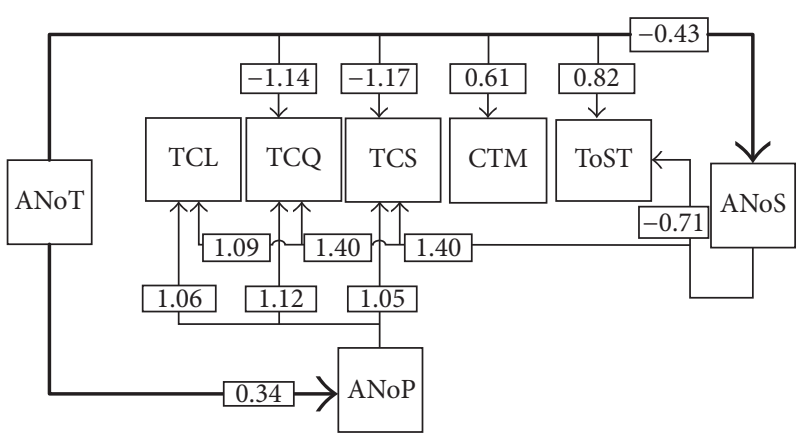

FIGURE 5: Influence mechanism of the male parent decision-making process.

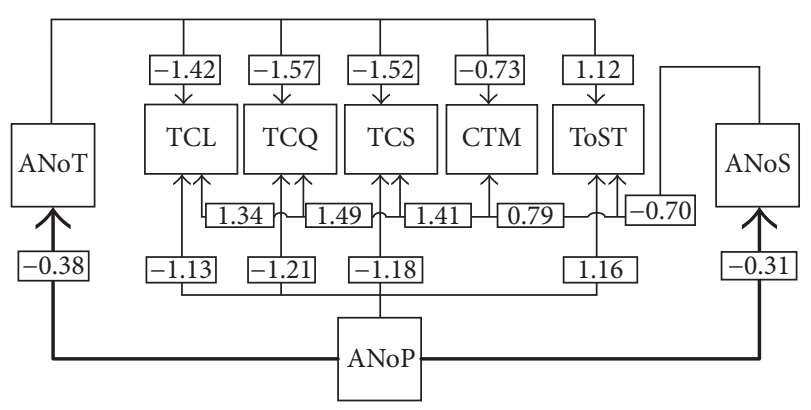

FIGURE 6: Influence mechanism of the female parent decisionmaking-process.

("personal" variables include commuting, recreation, and living activity-travel, whereas "household" variables include activity-travel with two or more family members.)

Figure 5 shows that the time dimension constraint was the most important factor during the decision-making process for male parents. If every unit increases for the time dimension constraint, 0.34 units would be increased in the space constraint, whereas the participant constraints would decrease by approximately 0.43 units. This result suggests that male parents generally compensate for the lack of spacetime resources by reducing their household activities when they cannot satisfy their own activity demands. Based on the results shown in Figure 6, enhanced participant constraints will decrease by 0.38 and 0.31 for time constraints and space constraints, respectively. These results indicate that female parents behaved in the opposite direction of their self-interests, where participant constraints were prioritized during the activity-travel decision-making process, and they tended to limit their personal activity needs, while prioritizing household tasks. The interaction model depicted in Figure 7 further indicates that when male parents reduce their household activities, these activities are transferred to the female parent: for example, if one hour of commute is added to the male parent, nearly 27 minutes $(60 \mathrm{~min} \cdot 0.83 \cdot 0.77$. $(-0.77) \approx-27 \mathrm{~min}$ ) of commute time is decreased for the female parent and 18 minutes of household work is added. In essence, household activity/travel does not "disappear" in the constraint but is instead transformed into different types of activity or behavior between parents as they cooperate with one another's constraints. This phenomenon from the secondary side demonstrates the previously described phenomenon in which, as a living collaboration, household members act as part of a living collaboration and prioritize the maximum benefit of the entire family unit over their own individual needs when there is a conflict between individual and household demands.

At the decision-making level, there are statistically significant differences in constraint strengths, although the constraint mechanisms were the same for both parents. Female parents are under tighter constraints than male parents. Figures 5 and 6 illustrate that activity arrangement efficiency of the male parent was affected by the female parent $(0.71)$ much more than the female parent activity affected the male parent (0.32), suggesting that the activity arrangement of male parents by and large controlled the decision-making process for the families surveyed. Other differences in behavioral decision-making included the following:

(1) The primary controlling influence of the activityconstraint niche of participant (ANoP) was household activities. As the demands of household activities increased, male parents attempted to accommodate them by reducing travel time, which complicated their travel models. However, female parents attempted to reduce their personal activities to assist other family members, which resulted in added travel time, less overall activity frequency, and simplified travel models.

(2) The activity-constraint niche of time (ANoT) dimension involves indices such as travel participant and travel type and combined mode sharing and time consumption for any single travel event. Under increased demand for time-fixed activities, all parents decreased their travel frequency and simplified their travel models, but there also were significant gendered discrepancies in the same family. Male parents tended to introduce complicated travel models, but female parents were more measured in taking detours or adding travel time.

(3) Changes in the spatial dimension reflected adjustments in trip-chaining length, number, and shape. As the demand for location-fixed activities increased, parents tended to complete activity-travel by adding travel time, reducing the time consumption of single trips, or connecting trips. In contrast to ANoP or ANoT, female parents were more willing to choose intermodal transfers in this instance, and males tended to select unitary modes to meet their travel demands.

Because of the rampant demand of individual commuting and household activity, and based on the results of the interaction modeling (Figure 7), Table 2 mainly shows the interactive utility of the individual commute and household activity after assuming that one hour of individual commute or household activity was added to the male and female parents. For instance, if the male parent added one hour 


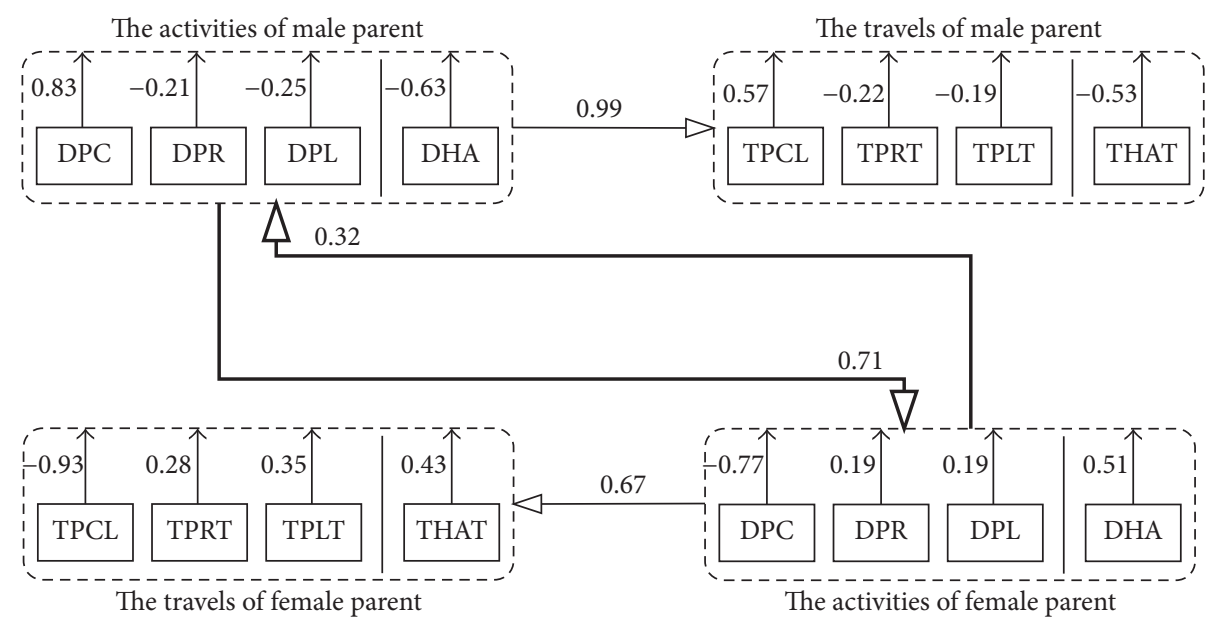

FIGURE 7: Interaction model between parents.

TABLE 2: The total effects of the individual commute and household activity-travel.

\begin{tabular}{|c|c|c|c|c|c|c|c|}
\hline \multirow{2}{*}{$\begin{array}{l}\text { Every additional one } \\
\text { hour in duration of } \\
\text { activity (min) }\end{array}$} & \multicolumn{2}{|c|}{$\begin{array}{c}\text { Time consumption of personal } \\
\text { travel }\end{array}$} & \multicolumn{2}{|c|}{ Duration of partner's activity } & \multicolumn{2}{|c|}{$\begin{array}{c}\text { Time consumption of partner's } \\
\text { travel }\end{array}$} & \multirow{2}{*}{$\begin{array}{c}\text { Time } \\
\text { left }\end{array}$} \\
\hline & $\begin{array}{c}\text { Individual } \\
\text { commute }\end{array}$ & $\begin{array}{c}\text { Household } \\
\text { activity }\end{array}$ & $\begin{array}{l}\text { Individual } \\
\text { commute }\end{array}$ & $\begin{array}{c}\text { Household } \\
\text { activity }\end{array}$ & $\begin{array}{l}\text { Individual } \\
\text { commute }\end{array}$ & $\begin{array}{c}\text { Household } \\
\text { activity }\end{array}$ & \\
\hline \multicolumn{8}{|l|}{ Male } \\
\hline Individual commute & +28 & -26 & -27 & +18 & -19 & +9 & -17 \\
\hline Household activity & -22 & +20 & +20 & -14 & +14 & -6 & +12 \\
\hline \multicolumn{8}{|l|}{ Female } \\
\hline Individual commute & +29 & -13 & -12 & +10 & -9 & +8 & +13 \\
\hline Household activity & -19 & +9 & +8 & -6 & +6 & -6 & -8 \\
\hline
\end{tabular}

to his individual activity time on a workday, he may spend approximately 28 minutes $(60 \mathrm{~min} \cdot 0.83 \cdot 0.99 \cdot 0.57 \approx 28 \mathrm{~min}$ ) in commute travel processing and concurrently cut down nearly 26 minutes $(60 \mathrm{~min} \cdot 0.83 \cdot 0.77 \cdot(-0.53) \approx-26 \mathrm{~min})$ in household activity-travel processing. Clearly, if the household has established that the male parent is responsible for commuting and the female for household affairs, household time utilization is maximized. These data conform to known traditional gender roles in Chinese nuclear families, in which the female parent tends to be more domestic and the male parent more social.

4.2. Goodness of Fit. The goodness of fit was adjusted for the decision-making models and interactive models by comparing the primary decision factors (Table 3). All model indices remained within the allowable range to ensure a perfect fit.

\section{Discussion and Conclusion}

There are growing concerns about the household factors in decision-making processing, as personal travel is completed within the framework of the household activity schedule. Interactive cooperation between family members, particularly parents, is a crucial factor for understanding activitytravel behavior. Previous studies generally focus on individual characteristics to define interactive efficiency, neglecting the fact that the variables for the constraints on group activities or for specific benefits of interactions must be considered on a relative basis. This study proposed the concept of a household activity constraint niche that measures total household efficiency based on two newly established models and explored the influence of various constraints on household decisionmaking. In addition, this study examined the manner in which effective decision-making benefits the entire family (as opposed to individuals) in a sample consisting of household travel survey data from Kunming, China.

This research provides empirical evidence that the spacetime resources of each activity-travel event can be considered the embodiment of behavioral constraints. When individuals attach purpose to an activity (when they must arrive at a fixed location at a fixed time), they are unable to participate in other activities. In determining the activities that follow, any surplus space-time resources are taken into account, as well as the needs of other family members who are dependent upon them. When conducting all necessary activity-travel in the framework of outside environmental constraints, the household as a whole does not generally ignore any possible activity-travel. However, it is more likely that activities are transferred between individual members spontaneously. The models created in this study demonstrate that activity-travel transfer was optimized at the space-time level and that families that engaged in behavioral-agent transmission effectively completed the necessary tasks even under constraints; that is, they reconciled individual demands with household 
TABLE 3: The goodness of fit of the models.

\begin{tabular}{|c|c|c|c|c|c|}
\hline & GFI & AGFI & PGFI & NFI & RFI \\
\hline Decision process of male parent & 0.909 & 0.912 & 0.586 & 0.917 & 0.926 \\
\hline Decision process of female parent & 0.918 & 0.927 & 0.572 & 0.930 & 0.907 \\
\hline Interactive mode of parents & 0.887 & 0.903 & 0.628 & 0.916 & 0.891 \\
\hline Reference value & $>0.9$ & $>0.9$ & $>0.5$ & $>0.9$ & $>0.9$ \\
\hline
\end{tabular}

demands. The results of this research suggest that individual decision-making behavior can be more clearly understood using a comprehensive analysis of household behavior. In addition, several improvements can be made in future studies. First, the proposed model can be used to account for the influence of day-to-day variation, particularly with respect to the different decision-making mechanisms on weekdays and weekends. Second, the calculation of constraint niches can be improved by considering real-time speed or travel distance. Third, the research objects and category also must be extended to include other family types, such as singleparent households, and an in-depth discussion should be included which focuses on the interaction mechanism under the influence of the household types. Finally, factors that cover changes in policy or environment should be added in future research, and a method should be proposed to quantify their influence on travel behavior.

\section{Notations}

Observation Variables Used in Established Model

\section{Activity-Constraint}

ANoT: Activity-constraint niche of time

ANoS: Activity-constraint niche of space

ANoP: Activity-constraint niche of participant

\section{Trip-Chaining Characteristic}

TCL: Trip-chaining activities' length

TCQ: Trip-chaining quantity in a workday

TCS: Trip-chaining shape, 1 if the shape of trip-chaining is multiple

ToST: Time consumption of single travel

CTM: Combination of mode shares, 1 if the person used more than one type of traffic tools in a workday

\section{Duration of Household and Individual Activities}

DPC: Duration of personal commuting

DPR: Duration of personal recreation

DPL: Duration of personal livelihoods

DHA: Duration of household activity

\section{Time Consumption of Household and Individual Travels}

TPCT: Time consumption of personal commuting travel
TPRT: Time consumption of personal recreation travel (including shopping)

TPLT: Time consumption of personal living travel

THAT: Time consumption of household activity-travel.

\section{Disclosure}

The original manuscript of this paper was presented at Transportation Research Board 95th Annual Meeting.

\section{Competing Interests}

The authors declare that there are no competing interests regarding the publication of this article.

\section{Acknowledgments}

The financial support from the Projects of International Cooperation and Exchange of the National Natural Science Foundation of China (no. 51561135003), the Key Project of National Natural Science Foundation of China (no. 51338003), and the Fundamental Research Funds for the Central Universities (no. KYLX15_0149) is gratefully acknowledged. The anonymous reviewers in that conference are greatly acknowledged for their help to improve this paper.

\section{References}

[1] T. Dubernet and K. W. Axhausen, "Implementing a household joint activity-travel multi-agent simulation tool: first results," Transportation, vol. 42, no. 5, pp. 753-769, 2015.

[2] J. Rose and D. A. Hensher, "Modelling agent interdependency in group decision making," Transportation Research Part E: Logistics and Transportation Review, vol. 40, no. 1, pp. 63-79, 2004.

[3] F. Liao, T. Arentze, and H. Timmermans, "Multi-state supernetwork framework for the two-person joint travel problem," Transportation, vol. 40, no. 4, pp. 813-826, 2013.

[4] C. R. Bhat, K. G. Goulias, R. M. Pendyala et al., "A householdlevel activity pattern generation model with an application for Southern California," Transportation, vol. 40, no. 5, pp. 10631086, 2013.

[5] J. Zhang, M. Kuwano, B. Lee, and A. Fujiwara, "Modeling household discrete choice behavior incorporating heterogeneous group decision-making mechanisms," Transportation Research Part B: Methodological, vol. 43, no. 2, pp. 230-250, 2009.

[6] A. I. Mosa and M. El Esawey, "An investigation of household interactions in daily in-home and out-of-home maintenance activity participation and social behavior in Cairo, Egypt," Transportation Letters, vol. 5, no. 4, pp. 201-212, 2013. 
[7] S. Y. Yoon and K. G. Goulias, "Impact of time-space prism accessibility on time use behavior and its propagation through intra-household interaction," Transportation Letters, vol. 2, no. 4, pp. 245-260, 2010.

[8] D. Hargen and G. Tanner, Behavioral Model of Mode Choice: Preliminary Report, New York State Department of Transportation, New York, NY, USA, 1970.

[9] A. T. Townsend, The Effects of Household Characteristics on the Multi-Day Time Allocations and Travel Activity Patterns of Households and Their Members, Northwestern University, Evanston, III, USA, 1987.

[10] L. J. V. Wissen, A Model of Household Interactions in Activity Patterns, Institute of Transportation Studies, University of California, Berkeley, Calif, USA, 1991.

[11] D. M. Scott and P. S. Kanaroglou, "An activity-episode generation model that captures interactions between household heads: development and empirical analysis," Transportation Research Part B: Methodological, vol. 36, no. 10, pp. 875-896, 2002.

[12] A. Kapur and C. R. Bhat, "Modeling adults' weekend daytime use by activity purpose and accompaniment arrangement," Transportation Research Record, no. 2021, pp. 18-27, 2007.

[13] H. J. P. Timmermans and J. Zhang, "Modeling household activity travel behavior: examples of state of the art modeling approaches and research agenda," Transportation Research Part B: Methodological, vol. 43, no. 2, pp. 187-190, 2009.

[14] H. J. Timmermans, "Analyses and models of household decision making processes," in Proceedings of the 11th International Conference on Travel Behaviour Research, Kyoto, Japan, 2006.

[15] O. Přibyl and K. G. Goulias, "Simulation of daily activity patterns incorporating interactions within households: algorithm overview and performance," Transportation Research Record, no. 1926, pp. 135-141, 2005.

[16] E. J. Miller and M. J. Roorda, "Prototype model of household activity-travel scheduling," Transportation Research Record, no. 1831, pp. 114-121, 2003.

[17] T. A. Arentze, D. Ettema, and H. J. P. Timmermans, "Incorporating time and income constraints in dynamic agent-based models of activity generation and time use: approach and illustration," Transportation Research Part C: Emerging Technologies, vol. 18, no. 1, pp. 71-83, 2010.

[18] H. Kato and M. Matsumoto, "Intra-household interaction in a nuclear family: a utility-maximizing approach," Transportation Research Part B: Methodological, vol. 43, no. 2, pp. 191-203, 2009.

[19] C.-H. Wen and F. S. Koppelman, "Integrated model system of stop generation and tour formation for analysis of activity and travel patterns," Transportation Research Record, no. 1676, pp. 136-144, 1999.

[20] P. Vovsha, E. Petersen, and R. Donnelly, "Model for allocation of maintenance activities to household members," Transportation Research Record, no. 1894, pp. 170-179, 2004.

[21] J. P. Gliebe and F. S. Koppelman, "Modeling household activitytravel interactions as parallel constrained choices," Transportation, vol. 32, no. 5, pp. 449-471, 2005.

[22] S. Srinivasan and C. R. Bhat, "Modeling household interactions in daily in-home and out-of-home maintenance activity participation," Transportation, vol. 32, no. 5, pp. 523-544, 2005.

[23] J. Y. J. Chow and W. W. Recker, "Inverse optimization with endogenous arrival time constraints to calibrate the household activity pattern problem," Transportation Research Part B: Methodological, vol. 46, no. 3, pp. 463-479, 2012.
[24] Y. Lee, M. Hickman, and S. Washington, "Household type and structure, time-use pattern, and trip-chaining behavior," Transportation Research Part A: Policy and Practice, vol. 41, no. 10, pp. 1004-1020, 2007.

[25] Y. Lee, S. Washington, and L. D. Frank, "Examination of relationships between urban form, household activities, and time allocation in the Atlanta Metropolitan Region," Transportation Research Part A: Policy and Practice, vol. 43, no. 4, pp. 360-373, 2009.

[26] J. P. Gliebe and F. S. Koppelman, "A model of joint activity participation between household members," Transportation, vol. 29, no. 1, pp. 49-72, 2002.

[27] D. Wang and J. Li, "A model of household time allocation taking into consideration of hiring domestic helpers," Transportation Research Part B: Methodological, vol. 43, no. 2, pp. 204-216, 2009.

[28] L. P. Gan and W. W. Recker, "A mathematical programming formulation of the household activity rescheduling problem," Transportation Research Part B: Methodological, vol. 42, no. 6, pp. 571-606, 2008.

[29] T. A. Arentze and H. J. P. Timmermans, "A need-based model of multi-day, multi-person activity generation," Transportation Research Part B: Methodological, vol. 43, no. 2, pp. 251-265, 2009.

[30] A. Justen, F. J. Martínez, and C. E. Cortés, "The use of space-time constraints for the selection of discretionary activity locations," Journal of Transport Geography, vol. 33, pp. 146-152, 2013.

[31] X. Fu, W. H. K. Lam, and Y. Xiong, "Modelling intrahousehold interactions in household's activity-travel scheduling behaviour," Transportmetrica A: Transport Science, vol. 12, no. 7, pp. 612-628, 2016.

[32] W. W. Recker, C. Chen, and M. G. McNally, "Measuring the impact of efficient household travel decisions on potential travel time savings and accessibility gains," Transportation Research Part A: Policy and Practice, vol. 35, no. 4, pp. 339-369, 2001.

[33] J. E. Kang and W. Recker, "The location selection problem for the household activity pattern problem," Transportation Research Part B: Methodological, vol. 55, pp. 75-97, 2013.

[34] T. Schwanen, D. Ettema, and H. J. Timmermans, "If you pick up the children, I'll do the groceries: spatial differences in between-partner interactions in out-of-home household activities," Environment \& Planning A, vol. 39, no. 11, pp. 27542773, 2007.

[35] H. Kang and D. M. Scott, "Exploring day-to-day variability in time use for household members," Transportation Research Part A: Policy and Practice, vol. 44, no. 8, pp. 609-619, 2010.

[36] J. Y. J. Chow and A. E. Nurumbetova, "A multi-day activitybased inventory routing model with space-time-needs constraints," Transportmetrica A: Transport Science, vol. 11, no. 3, pp. 243-269, 2015.

[37] M. J. Roorda, J. A. Carrasco, and E. J. Miller, "An integrated model of vehicle transactions, activity scheduling and mode choice," Transportation Research Part B: Methodological, vol. 43, no. 2, pp. 217-229, 2009.

[38] C. Ho and C. Mulley, "Intra-household interactions in transport research: a review," Transport Reviews, vol. 35, no. 1, pp. 33-55, 2015.

[39] T. Hägerstrand, "What about people in regional science?" Papers of the Regional Science Association, vol. 24, no. 1, pp. 6-21, 1970.

[40] H. J. Miller and S. Bridwell, "A field-based theory for time geography," Annals of the Association of American Geographers, vol. 99, no. 1, pp. 49-75, 2009. 
[41] X. Liu, W. Y. Yan, and J. Y. J. Chow, “Time-geographic relationships between vector fields of activity patterns and transport systems," Journal of Transport Geography, vol. 42, pp. 22-33, 2015.

[42] H. Kang and D. M. Scott, "An integrated spatio-temporal GIS toolkit for exploring intra-household interactions," Transportation, vol. 35, no. 2, pp. 253-268, 2008.

[43] T. A. Arentze and H. J. P. Timmermans, "A learning-based transportation oriented simulation system," Transportation Research Part B: Methodological, vol. 38, no. 7, pp. 613-633, 2004. 


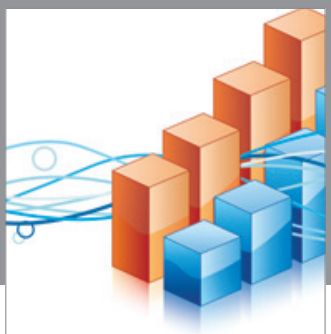

Advances in

Operations Research

vatem alat4

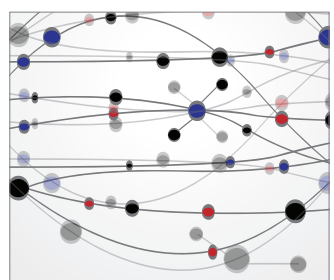

\section{The Scientific} World Journal
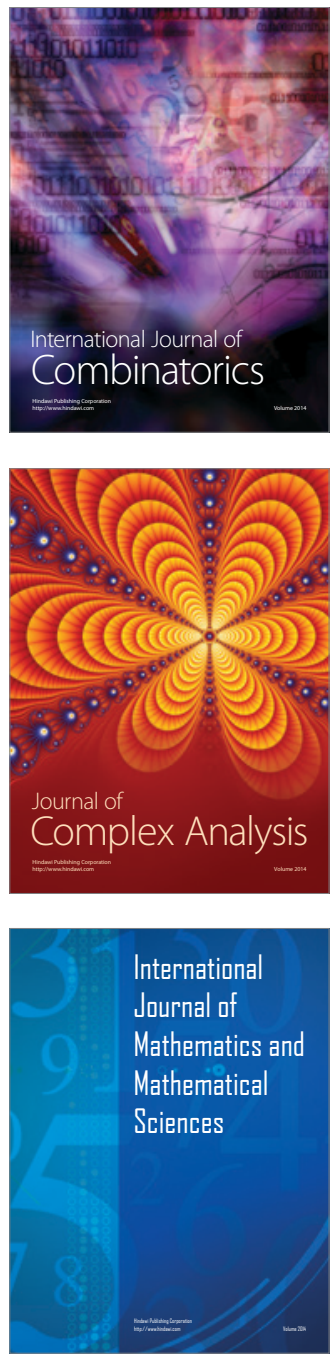
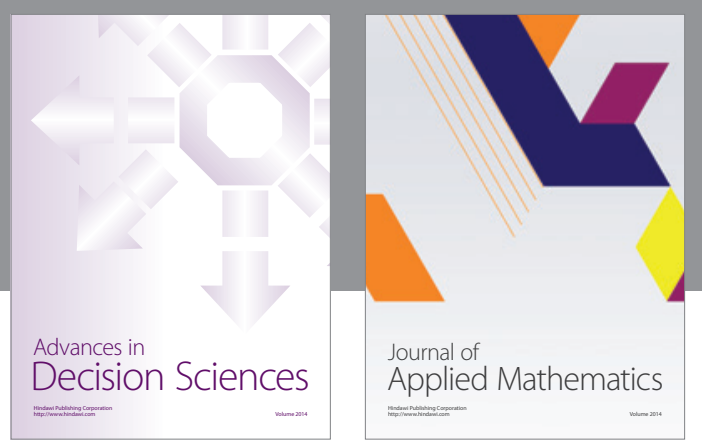

Algebra

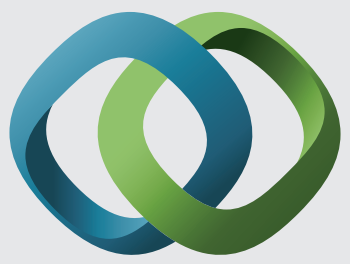

\section{Hindawi}

Submit your manuscripts at

https://www.hindawi.com
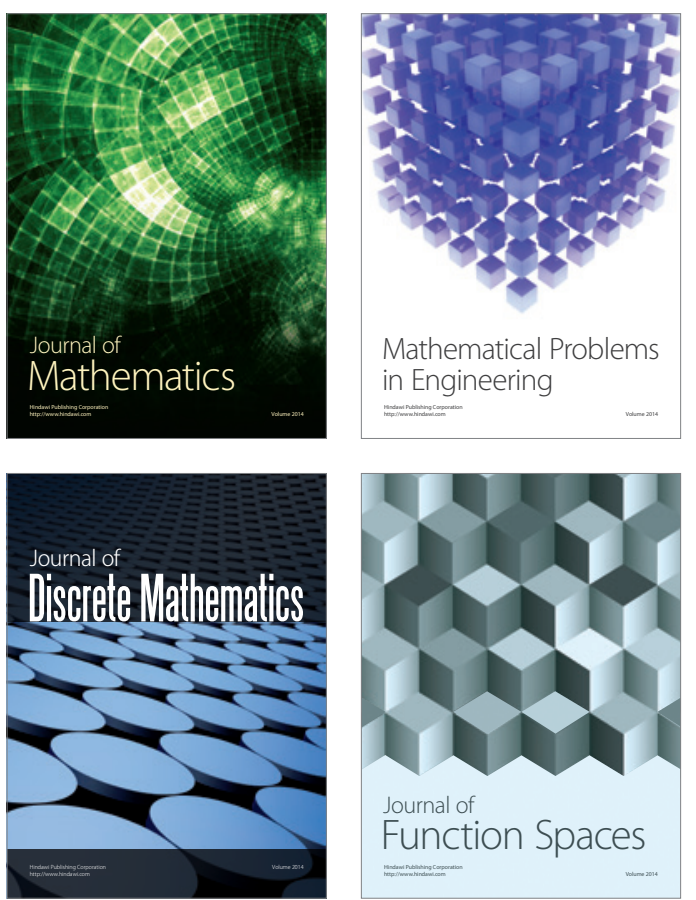

Mathematical Problems in Engineering
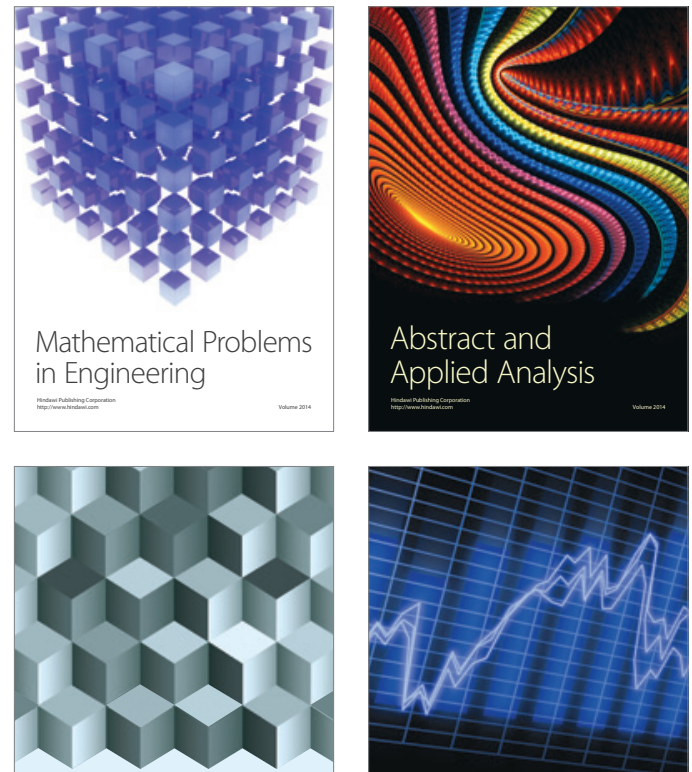

Journal of

Function Spaces

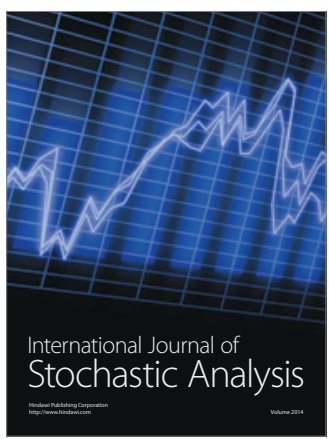

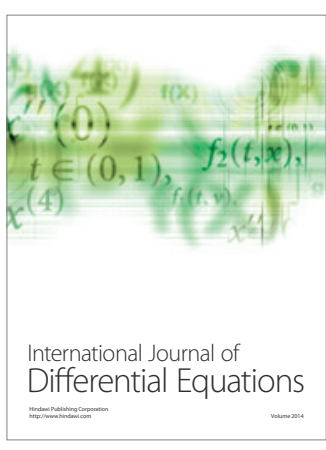
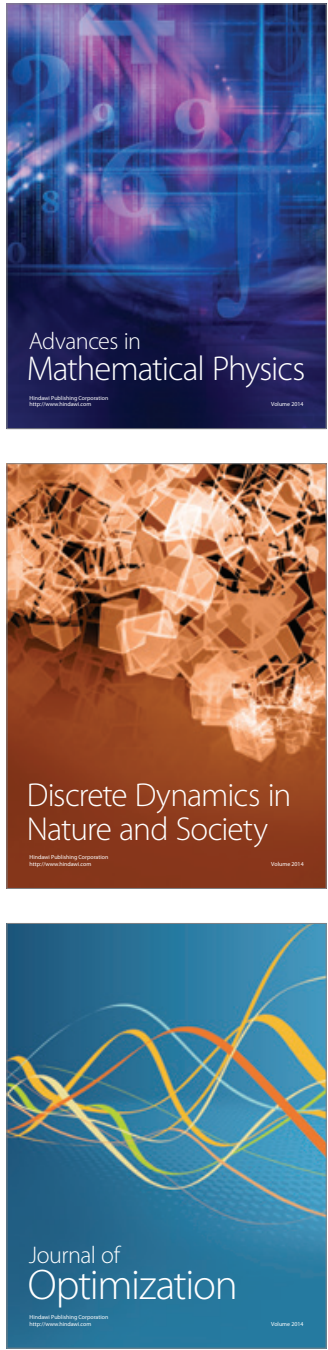